\title{
ARTICLES \\ My Meat Does Not Have Feathers: Consumers' Associations with Pictures of Different Chicken Breeds
}

\author{
Cynthia I. Escobedo del Bosque ${ }^{1}$ D $\cdot$ Gesa Busch $^{1} \cdot$ Achim Spiller $^{1} \cdot$ Antje Risius $^{1}$
}

Accepted: 3 November 2020 / Published online: 18 November 2020

(c) The Author(s) 2020

\begin{abstract}
The use of traditional chicken breeds with a dual purpose (egg and meat production) has become a relevant topic in Germany mainly due to animal welfare concerns and the importance of conserving genetic variability in poultry farming. However, consumers have little knowledge about the different chicken breeds used in the industry; making it challenging to communicate traditional breeds and their advantages to consumers. Hence, this study takes the approach to look at consumers' perceptions of different breeds. We analyze consumers' evaluations of pictures showing four dual-purpose chicken breeds. First, an eye-tracking study $(\mathrm{n}=24)$ and thinkaloud protocols $(n=28)$ were used to obtain open associations consumers make with each breed. Based on the results, an online survey was conducted $(n=933)$ to quantify consumers associations with different breeds and consumers' interest in meat products with animal pictures on the packaging. Results show that consumers' attention to pictures of chickens is mostly focused on their body and head, particularly with the Vorwerkhuhn. Consumers associate white breeds to white egg and meat production, while brown breeds are associated to brown egg production. Only a smaller segment of consumers $(32 \% ; n=292)$, who are more engaged to animal welfare, accept pictures of animals on meat packages. We conclude that the marketing of meat products of traditional chicken breeds by using pictures is not a useful approach for the mass market. However, within smaller market concepts, such pictures can be used to communicate an alternative chicken meat production system that may lead to purchases of traditional dual-purpose breeds.
\end{abstract}

Keywords Picture evaluation · Image association · Traditional chicken breed $\cdot$ Meatparadox

Cynthia I. Escobedo del Bosque cynthia.escobedo@uni-goettingen.de

Extended author information available on the last page of the article 


\section{Introduction}

Intensive animal production methods that include specialized environments have gained popularity since the late 1940's (Fraser 2008). Producers have selected specialized chicken breeds to achieve a higher performance at comparably low cost. Although these specialized breeds provide economic benefits, such as fast growth rates, high laying or fattening performances, and good feed use efficiencies, they give concern to animal health and welfare as well as to ethical questions (Leenstra et al. 2011). Among these ethical concerns is the killing of day-old male chicks of the laying breeds, which is commonly practiced in the commercial production of eggs in organic and conventional farming, since fattening males of laying breeds is not profitable (Leenstra et al. 2011). In Germany alone, nearly 45 million male chicks are annually killed due to non-profitability (BMEL 2019).

The culling of male chicks raises ethical concerns among consumers (Aerts et al. 2009). The mass killing of "baby" animals that are considered a "by-product" of an intensive production method is a common reason for the dislike of this practice, since people perceive that the animals are seen as "instruments" or "objects" rather than subjects by the industry (Bruijnis et al. 2015). Increasing interest in this topic has led to the development of various alternatives. Among these alternatives is the use of dual-purpose breeds (DPBs) that can be used for egg production (female animals) and broiler production (male animals) (Damme 2015; Krautwald-Junghanns et al. 2018). However, the concept of DPBs is not familiar to most consumers (Gangnat et al. 2018; Brümmer et al. 2017; Busse et al. 2019). Nonetheless, when introduced to this alternative, consumers see it as a positive practice that is more animal-friendly and ethically justifiable (Gangnat et al. 2018; Brümmer et al. 2017; Leenstra et al. 2011; Busse et al. 2019). Nowadays, there are commercial DPBs available such as Lohmann Dual (Lohmann Tierzucht GmbH, Cuxhaven, Germany), and traditional DPBs that have a lower fattening/laying performance (Mueller et al. 2018), for example Vorwerkhuhn, which are used rarely on farms.

The dominance of few breeds in commercial poultry production has resulted in a low genetic variability in the market. Conservation of traditional breeds has the potential to increase genetic variability (Spalona et al. 2007; Weigend et al. 2009; Padhi 2016). Projects aimed to establish and maintain a flock of chickens of the Vorwerkhuhn breed have helped remove this breed from risk of extinction (BLE 2019). Additionally, traditional breeds are also crucial for the economy of small-scale (or household) farming (Padhi 2016), due to the breeds' robustness and their "forage-hunter" behavior (Padhi 2016; BLE 2019). This forage-hunter behavior allows breeders to feed the animals with "kitchen waste", wheat, grass, insects, etc. (Padhi 2016) and avoid depending solely on commercial feedstuff which contains soy beans. Traditional breeds could offer small-scale farmers an opportunity to target niche markets which have aroused from a demand of more specialized food and more ethical production methods.

However, the marketing of traditional animal breeds is difficult because consumers generally seem to have little knowledge about animal breeds. It is difficult 
to explain the benefits of animal breeds in view of the alienation of many consumers from agriculture due to a growing urbanization (Albersmeier and Spiller 2008, Böhm et al. 2009). Many consumers have no idea that animals are specifically bred for meat or egg production (Gangnat et al. 2018).

An innovative way of introducing traditional DPBs to consumers could be through the use of pictures in marketing, since they might have the potential to attract attention, convey an emotional message and to indicate differences in the breed and therefore in the product for interested consumers. In fact, some traditional breeds look very specific or conspicuous. However, pictures of living animals on meat products are rarely used for marketing purposes. This might be attributed to the so-called "meat-paradox". This paradox refers to many people liking to eat meat but disliking killing animals or causing them pain (Loughnan et al. 2010).

The state of discomfort described in the meat-paradox (resulting from the liking of meat but the disliking of being aware about the participated responsibility for animal well-being) was first referred to as cognitive dissonance (Festinger 1957). Usually, people try to avoid such mental states of dissonance. One approach to avoid these states of dissonance is by changing behavior or attitudes (Harmon-Jones and Harmon-Jones 2007; Piazza et al. 2015). Meat changing behavior might lead to some consumers following their attitudes and eating less meat or preferring to eat 'better' meat; others might reduce or suppress their moral concerns for animals while keeping animal products' consumption stable (Kunst and Hohle 2016; Piazza et al. 2015).

There is little empirical research testing the meat-paradox specifically with chicken meat (e.g. Kunst and Hohle 2016) and to the best of our knowledge, there is no empiric research testing the meat-paradox that might result when people see pictures of chickens on animal products. This is of particular interest since the results might vary from studies with mammals because studies have shown that people feel more empathy towards mammals (e.g. pigs) and less empathy towards birds (Kubberød et al. 2002; Westbury and Neumann 2008).

Research related to the marketing of animal products based on animal breeds is limited. In these cases, the marketing of a specific breed mostly focuses on the animals' origin (Verrier et al. 2005; Belk et al. 2014), genetic conservation of the species (Frison and Coolsaet 2018; BESH 2019), or a specific attribute of the product (Wahl et al. 1995). Perhaps the most popular example of breed marketing in poultry is the case of France's Bresse chicken which is marketed mainly based on its origin (Bresse region, France) and traditional breeding (Verrier et al. 2005; La Volaille de Bresse 2015).

While these studies show that animal origin and traditional breeding are of importance for the marketing of animal products of specific breeds, to the best of our knowledge, there is no empirical research on how consumers perceive pictures of chicken breeds, what they associate with the breeds, and if such pictures could be used to help market meat from traditional breeds. This topic is especially important for countries like Germany, where there is no well-known traditional chicken breed, as opposed to France where the strong desire for traditional agricultural products led to the development of "AOC" (controlled designation origin) for the Bresse chicken (visually well-known for its blue legs, white plumage and red crest) to protect its 
traditional production method and the breed itself (Fermet-Quinet and Bussière 2010).

Today's poultry production is characterized by breeds for egg production and breeds for meat production. The market is dominated by the large breeding companies, leading to very limited breed diversity in poultry production. The use of traditional breeds could help preserve genetic biodiversity in poultry production and could offer opportunities for small-scale farmers to gain a competitive advantage. Further, such traditional breeds can often be used for dual purposes and by doing so, preventing the killing of day-old-chicks which is a contentiously discussed practice.

From a marketing perspective, the main challenge is the lack of consumers' awareness of different breeds which generates problems to communicate such breeds and their advantages to consumers. As consumers today are very distanced from agriculture, textual information could be very difficult to transmit. They would require a high level of consumer involvement, which is typically rare. Information about traditional breeds could be increased through pictures of the animals. The danger is that this might cause cognitive dissonance (meat-paradox) and, in the worst case, has the opposite effects, namely an orientation of consumers towards other meat products without pictures such as conventional ones.

Therefore, the aim of this study is to gain a better understanding of consumers' evaluation and acceptance of pictures showing chicken breeds in the context of marketing. The following research questions (RQ) were investigated:

- What raises consumers' awareness when looking at pictures of different chicken breeds? (RQ1)

- Which associations do consumers have with different breeds? (RQ2)

- Do consumers like to see a picture of the animal when purchasing chicken meat? (RQ3)

We hypothesize that diverse chicken breeds are perceived differently among consumers due to their variance in phenotype. Additionally, we hypothesize that chicken meat, although usually perceived differently (i.e., healthier, classified as white meat, less empathy with birds) compared to red meat (Kubberød et al. 2002), also suffers from the "meat-paradox"-effect since animals also have to be killed for consumption. Nonetheless, we expect a small group of animal welfare concerned consumers, our niche market, to accept and moreover, to be interested in seeing such pictures even on products.

\section{Methods}

The present study combines two methodological approaches. First, an exploratory test consisting of an eye-tracking study and a think-aloud method was carried out. Then, results obtained were used to develop a standardized online questionnaire to test consumers' associations with chicken pictures in a bigger population.

We chose five chicken breeds for the study to be presented to consumers: 
1. Bresse Gauloise (BG): a French DPB known for its sensory qualities; also commonly bred in Germany due to its good laying/fattening performance.

2. Vorwerkhuhn (VH): a German DPB which has been bred to prevent the extinction of the species.

3. White Rock (WR): a commercial line used for egg production, occasionally used as DPB.

4. Kollbecksmoor (KM): a dual-purpose crossbreed of Vorwerkhuhn and White Rock; used due to its good laying/fattening performance.

5. Lohmann Brown (LB): a commercial line used for meat production from one of the leading international breeding companies.

These particular breeds were chosen to test any difference between two commercial lines (WR for eggs, LB for meat) and three locally bred DPBs (BG, VH, $\mathrm{KM}$ ). Within the poultry industry there are different animal lines, breeds and crossbreeds. However, to ease lecture, from this point on we refer to all of these as "breeds".

In both studies, all participants gave written informed consent to take part in the study before the experiment started. Both studies were conducted in accordance with the Declaration of Helsinki, and both protocols were approved by the Ethics Committee of the University of Goettingen.

\section{Exploratory Study: Eye-Tracking and Think Aloud Method}

Eye-tracking (ET) is a method used to investigate eye movements in order to understand human information reception, i.e. attraction and awareness of particular areas in specific stimuli (Duchowski 2002). Eye movements are categorized in (1) saccades, or rapid eye movements, and (2) fixations, which are moments when the eye is still and focused (Wedel and Pieters 2006; Balcombe et al. 2015). With eye-tracking, the unconscious movements of the pupil can be recorded and give hints on what attracts peoples' attentions.

All eye movements were recorded by the Tobii Pro Glasses 2 (Version 1.67.7669, Tobii AB, Stockholm). This head unit consists of four eye cameras, one high definition scene camera in the front, two sensors, and one microphone (Tobiipro 2016). The glasses register and measure each participant's pupil movement through the presented images and their areas of interest (AOI). These AOIs are delimited regions of the picture that are defined by the researcher because they are of interest for answering the research question.

Think-aloud (TA) is a method in which participants perform a specific task and are asked to simultaneously vocalize what they are thinking or doing. These results, called protocols, are then used for analysis to better understand problemsolving processes (van Someren et al. 1994). However, in this study, this method was used to analyze the perception of images through participants' vocalization of their thoughts when looking at a picture. 


\section{Study Design}

A sample of twenty-eight adults (aged 20-61 years) was recruited at the University of Goettingen in Germany during October and November 2017. All participants consumed chicken meat and eggs at least once a month. Participants were equipped with a Tobii Pro Glasses 2 Eye-Tracker (Version 1.67.7669, Tobii AB, Stockholm). The eye-tracker was individually calibrated by measuring participants' specific eye movement characteristics. All pictures used in the study were presented on a 23.8inch flat screen with a 1920x1080 resolution (DELL, Hamburg), placed about 70 to $80 \mathrm{~cm}$ from the head of the participants (Tobiipro 2016) for fifteen seconds with a three second pause after each picture.

The stimuli used for the experiment were a total of ten pictures showing five different chicken breeds: Bresse Gauloise (BG), Vorwerkhuhn (VH), White Rock (WR), Lohmann Brown (LB), and Kollbecksmoor (KM). We selected three major AOIs for each animal: (1) head, (2) body, and (3) feet. Each AOI was manually delimited in each picture by the researcher. To test whether participants' attention to the AOIs changes with different backgrounds, we tested a white and natural (grass) background for each breed. All in all, each picture showed an individual animal at the same age. Figure 1 shows the different AOIs of two BG chickens in a white and grass background, as an example. Pictures of BG, VH, WR and KM were taken by a professional animal photographer at a farm in Bad Laer (Lower Saxony, Germany) with consent from the breeder and farm owner. Pictures of LB were purchased from Fotolia (Adobe, New York) and modified by the photographer in order to have a similar grass background to the rest. Similarly, pictures of BG, VH, WR and KM were modified by the photographer to obtain a white background.

The study consisted of three different parts: first participants were asked to observe five pictures of different chicken breeds: BG, VH, WR, LB, and KM with

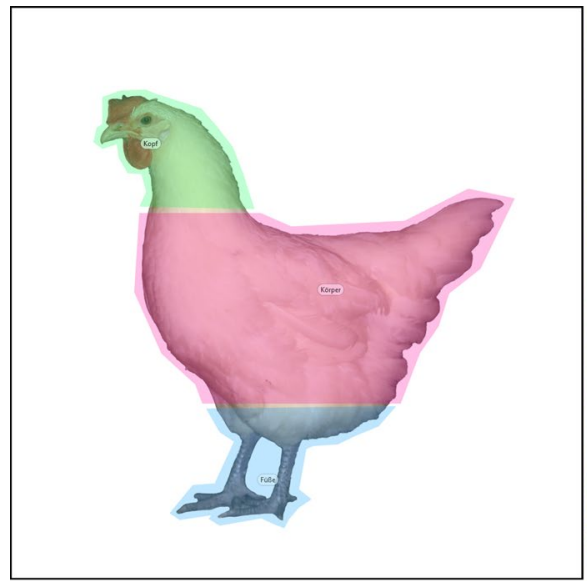

(a) White background

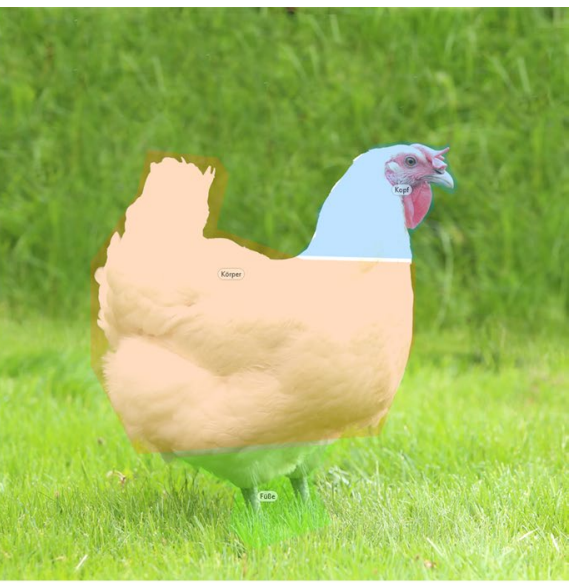

(b) Grass background

Fig. 1 Areas of interest for Bresse Gauloise with $\mathbf{a}$ white and $\mathbf{b}$ grass backgrounds 
a white background. Second, participants were given the following instructions "Please say out loud what you think of the chickens in the following pictures" and then pictures of the same chickens with the natural background were shown and participants' thoughts were recorded. All pictures were randomized to avoid order effects. Third, participants were asked how many chicken breeds they had seen, if they were familiar with any chicken breeds and if they recognized one or more breeds.

\section{Data Analysis}

Two participants had a gaze sample percentage of $52 \%$ and $44 \%$, while the average of the remaining twenty-six participants was 93\%; this indicated that for these two participants one eye or both eyes were found only for about half of the recording. This low gaze sample percentage can be a reflection of configuration errors, difficulty to track a participant, light interferences, etc. (Tobiipro 2018). Holmqvist et al. (2012) present different methods and examples of how to deal with data quality of eye tracking measurements. In order to keep a gaze sample percentage of approximately $90 \%$ (5-10\% data loss is caused by blinking) these two participants were excluded, resulting in 26 participants that remained for the ET analysis. However, in order to gather as many observations as possible, all 28 participants were considered for the TA.

All ET data were saved and processed on the Tobii Pro Lab Software (Version 1.67.7669, x64, Tobii AB, Stockholm). Fixations data for each AOI was collected, processed and filtered (by a Velocity-Threshold Filter) from raw data by the software and later obtained as an Excel file with results for each participant. Results were saved in the following metrics: (1) fixation duration-the duration of each individual fixation within one AOI, (2) fixation count-number of fixations the participant gives to a specific AOI, (3) visit duration-duration of each individual visit to a specific AOI, and (4) visit count - the number of visits on an active AOI (Tobiipro 2016).

The software also provides the researcher with heat maps by using the average amount of fixations in the stimuli. These heat maps are graphical representations of how fixations are distributed over the stimulus (Raschke et al. 2014). These maps use different colors to show the amount of fixations in a particular area: the red color indicates areas with the most fixations, red then turns into orange/yellow to show fewer amount of fixations, while the green color indicates areas with the least amount of fixations (Tobiipro 2016). It should be noted that the heat maps do not refer to the AOIs but to single data points in the pictures. All other statistical analysis, i.e. means $(\mu)$, standard deviations $(\sigma)$, analysis of variance (ANOVA) and post hoc tests were calculated using SPSS (Version 26, IBM, New York).

All TA protocols were recorded with a voice recorder (LS-14, Olympus). First, protocols were transcribed and segmented following van Someren et al. (1994). Next, a coding scheme was constructed, following van Someren et al. (1994), based on the categories presented in Table 1. Finally, words mentioned in the categories of "subjective description: animals" and "others: consumption association" were used for the online survey. 
Table 1 Categories used for think aloud protocol measurements

\begin{tabular}{lll}
\hline Category & Subcategories (assigned code) & Examples \\
\hline Objective description & Animal (OA) & White, yellow feet \\
& Background (OB) & Green, grass \\
Subjective description & Animal (SA) & Happy, aggressive \\
& Background (SB) & Free-range \\
Others & Consumption association (OCA) & Meat, eggs \\
& Breed related (OBR) & Same breed, "X" breed \\
& Others (OO) & \\
\hline
\end{tabular}

Since this study was used as a basis for the online survey, only results of BG, VH, WR and KM will be presented. The breed Lohmann Brown was not included in the survey since it is not a traditional breed. Aditionally, participants showed the same fixation pattern in pictures with both backgrounds, therefore only results of pictures with a grass background, which were then used for the online survey, will be presented in the results section.

\section{Online Survey}

\section{Study Design}

A sample of 1100 participants was recruited by a professional online provider (Respondi AG) during July and August 2018 in Germany. The sample was selected by a quota sampling procedure with gender, age, education, and income, to achieve representativeness of the German population with regard to these categories.

Participants were screened according to their consumption behavior: only participants who consume chicken meat at least once a month were selected. Additional questions regarding participants' consuming and buying patterns were asked: chicken meat and egg consumption and buying frequency, as well as buying frequency of regional, organic, and animal products with animal welfare labels. Afterwards respondents' attitudes to the meat-paradox were measured with a total of sixteen statements presented in Table 2. These statements were quantified using a 7-point Likert scale ranging from 1) I totally agree to 7) I totally disagree, with "neither nor" as a mid-point on the scale. All items were randomized to prevent systematic order effects.

The following part of the survey showed participants all four pictures (same pictures as in the exploratory study described in Sect. 2.1) in a randomized order. Figure 2 shows the pictures that participants evaluated in the survey.

Each picture was presented along with eighteen pairs of words on a 7-point semantic differential scale. For each of the pairs, participants could indicate their answer between two opposite words (e.g. "pretty" and "ugly"), marked from 1 (positive adjective) to 7 (negative adjective) for analysis. Table 3 presents the eighteen pairs of opposite words which participants rated. 
Table 2 Statements related to the meat-paradox used in the survey Source: Authors' own elaboration and ${ }^{1}$ Rothgerber (2013), ${ }^{2}$ Bastian and Loughnan, (2016), and ${ }^{3}$ Ermann (2018)

\begin{tabular}{|c|c|}
\hline & Wording \\
\hline 1 & I would like to see what the animal looked like before it was slaughtered \\
\hline 2 & I would like to buy meat with pictures of the animals on the package \\
\hline 3 & When I see chicken meat, I try not to associate it with an animal ${ }^{1}$ \\
\hline 4 & I do not like to think about where the chicken meat I eat comes from ${ }^{1}$ \\
\hline 5 & I am aware that I eat living beings ${ }^{1}$ \\
\hline 6 & $\begin{array}{l}\text { The thought that chickens as living animals are later consumed for human nutrition is unpleas- } \\
\text { ant to } \mathrm{me}^{3}\end{array}$ \\
\hline 7 & If I knew how chickens are slaughtered and cut, I would no longer eat their meat ${ }^{3}$ \\
\hline 8 & I like the sight of raw meat ${ }^{3}$ \\
\hline 9 & I am aware of the slaughtering process when eating meat ${ }^{3}$ \\
\hline 10 & I feel with animals ${ }^{2}$ \\
\hline 11 & It is necessary that animals are kept for our nutrition ${ }^{2}$ \\
\hline 12 & Animals are doing well in today's animal husbandry ${ }^{2}$ \\
\hline 13 & I cannot do anything about the system of animal husbandry today ${ }^{2}$ \\
\hline 14 & I think that politics should do something about the system of animal husbandry ${ }^{2}$ \\
\hline 15 & When I buy meat, I try to ensure that animals are kept in good conditions ${ }^{2}$ \\
\hline 16 & I will try to ensure that there are better conditions for keeping animals ${ }^{2}$ \\
\hline
\end{tabular}

Then, the same picture appeared and participants' association of this picture to meat or egg production/consumption was measured with the following statements: (1) This chicken is suitable for meat production, (2) This chicken is suitable for egg production, (3) This chicken will certainly lay many eggs, (4) It looks as if it lays brown eggs, (5) It looks as if it lays white eggs, and (6) This chicken is well suited for the grill. These were evaluated using a 7-point Likert scale from (1) I totally agree to (7) I totally disagree, with "neither nor" as a mid-point in the scale. All pictures and statements were randomized to avoid order effects.

Finally, consumers' direct association of pictures with products they had consumed was measured with the following questions: "Please remember the last time you consumed chicken meat. Which picture comes to your mind?" and "Please remember the last time you consumed eggs. Which picture comes to your mind?" Participants had to choose between the pictures of BG, VH, WR, KM or "I do not know".

\section{Data Analysis}

A total of 977 participants completed the survey. After data cleaning (participants who needed less than half of the average response time or more than twice the 


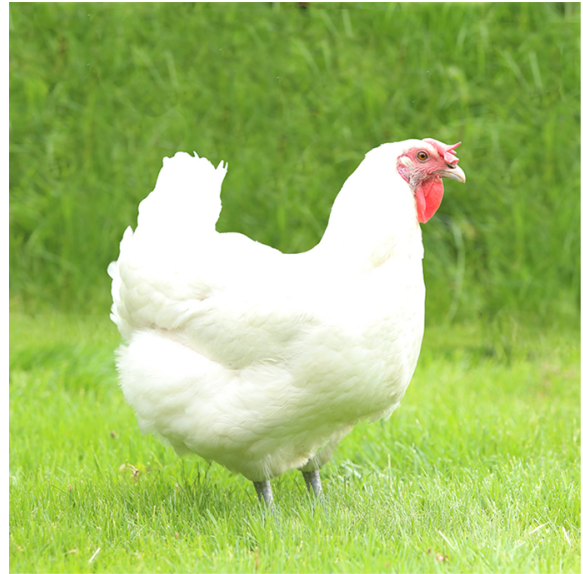

(a) Bresse Gauloise

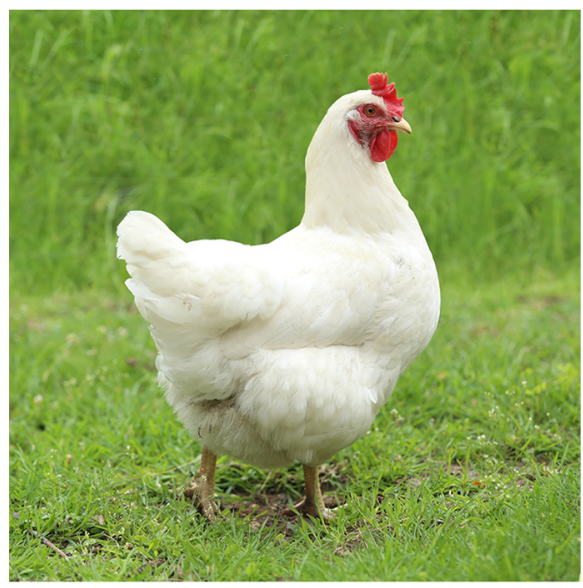

(c) White Rock

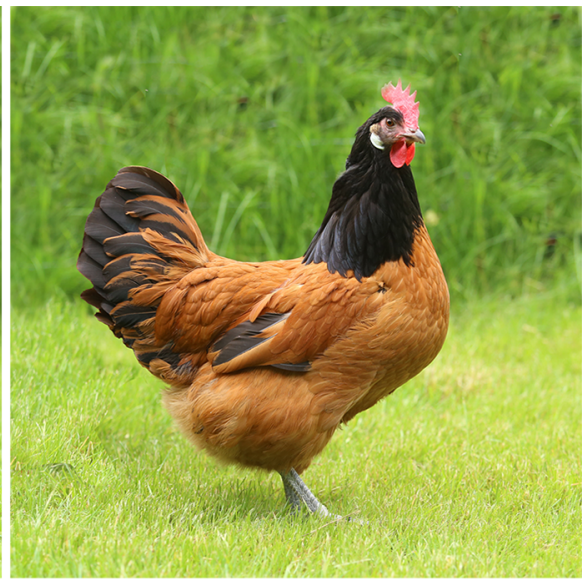

(b) Vorwerkhuhn

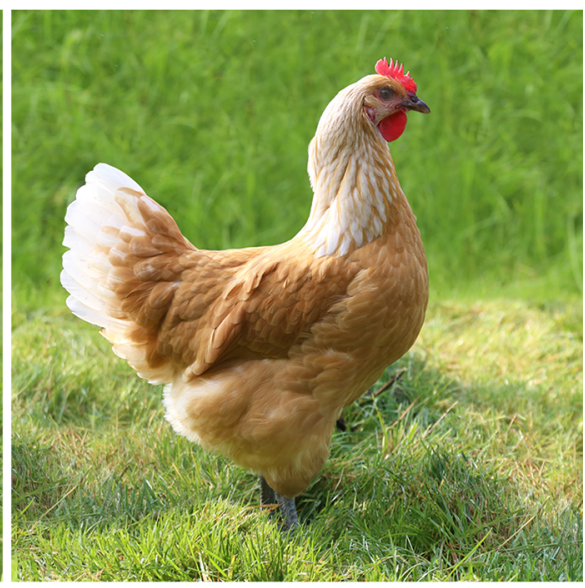

(d) Kollbecksmoor

Fig. 2 Pictures used for participants' evaluation of each breed: a Bresse Gauloise, b Vorwerkhuhn, c White Rock, d Kollbecksmoor

average response time), the total sample was reduced to 933 participants. All statistical analyses were carried out using SPSS (Version 26, IBM, New York).

Initially, descriptive statistics were calculated. Next, to analyze the differences between breeds on the semantic differential scale, an ANOVA with post hoc tests Tukey for variance homogeneity and Games-Howell for variance heterogeneity was calculated. Finally, all meat-paradox items were analyzed and participants that indicated to be interested in seeing pictures of animals and seeing what the animals looked like before slaughter were grouped based on their responses: participants that answered from "I totally agree" to "neither nor" in both statements 
Table 3 List of words used for semantic differential

\begin{tabular}{|c|c|c|}
\hline Pair & Positive & Negative \\
\hline 1 & Typical chicken ${ }^{1}$ & Exotic chicken $^{1}$ \\
\hline 2 & Nice color ${ }^{1}$ & Ugly color $^{1}$ \\
\hline 3 & Happy $^{1}$ & $\mathrm{Sad}$ \\
\hline 4 & Healthy ${ }^{1}$ & Unhealthy \\
\hline 5 & Fat/inflated ${ }^{1}$ & Thin $^{1}$ \\
\hline 6 & $\operatorname{Big}^{1}$ & Small $^{1}$ \\
\hline 7 & Natural $^{1}$ & Overbred $^{1}$ \\
\hline 8 & Well-shaped & Shapeless \\
\hline 9 & Robust & Fragile \\
\hline 10 & Strong $^{1}$ & Weak \\
\hline 11 & Old $^{1}$ & Young \\
\hline 12 & Calm $^{1}$ & Aggressive $^{1}$ \\
\hline 13 & Pet & Wild animal $^{1}$ \\
\hline 14 & Agile $^{1}$ & Sluggish \\
\hline 15 & Well-fed $^{1}$ & Rickety \\
\hline 16 & Tasty & Disgusting \\
\hline 17 & Appetizing $^{1}$ & Unappetizing \\
\hline 18 & Proud $^{1}$ & Crouched \\
\hline
\end{tabular}

${ }^{1}$ Taken directly from $\mathrm{TA}$ results

were grouped. Their responses on the meat-paradox items were compared to the rest of participants with an ANOVA.

\section{Results}

\section{Consumers' Observations When Presented with Pictures of Different Chicken Breeds (RQ1)}

In the ET study $(n=26)$, participants were mostly men $(54 \%)$, between the ages of 20 and $30(58 \%)$ and had a university degree (70\%). Most participants consumed chicken meat and eggs at least once a week (64\% and $81 \%$, respecively). The majority of participants (89\%) was not familiar with chicken breeds and $96 \%$ could not identify any breed in this study. The only breed that was identified by one person was $\mathrm{VH}$.

Figure 3 shows each breed's individual heat map based on the amount of fixations. These maps show that the main focus on all pictures is the head/face of the animal, followed by the body. Additionally, participants also focused more on the bodies of $\mathrm{VH}$ and $\mathrm{KM}$.

Table 4 shows the means and standard deviations of fixation counts and fixation duration for each area of interest for each breed. There was no difference in fixating the heads of the animals between breeds. On the other hand, the AOIs body and feet showed differences $(p \leq 0.05)$ between breeds. The AOI body had higher fixation 


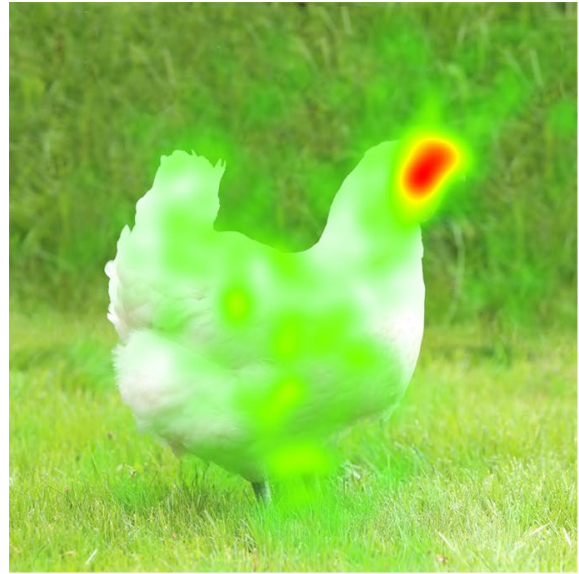

(a) Heat map of Bresse Gauloise

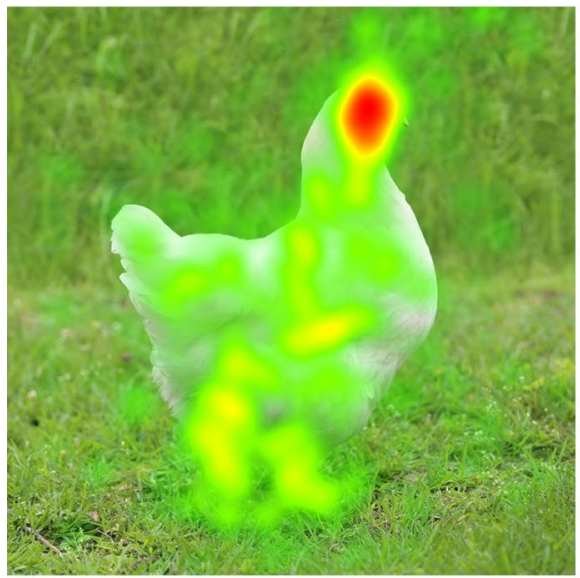

(c) Heat map of White Rock

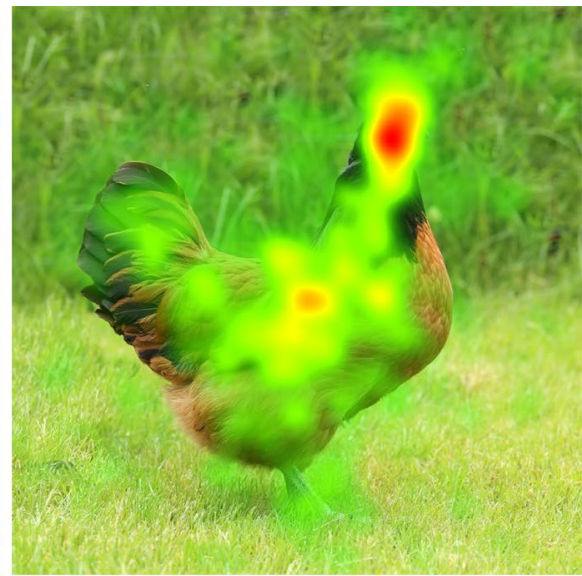

(b) Heat map of Vorwerkhuhn

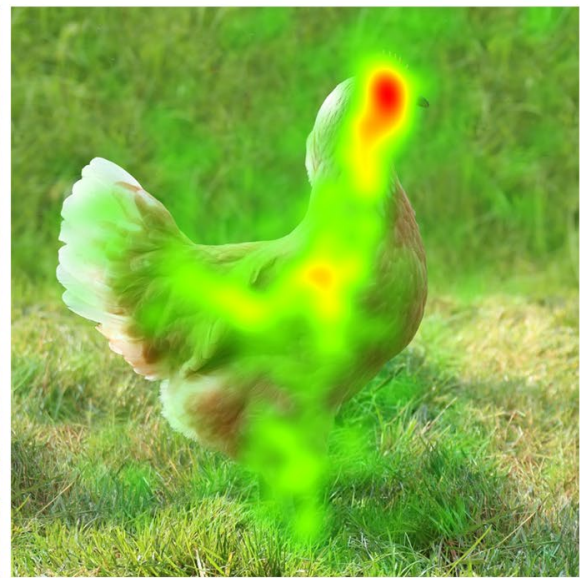

(d) Heat map of Kollbecksmoor

Fig. 3 Heat maps based on amount of fixations for the four breeds: a Bresse Gauloise, b Vorwerkhuhn, c White Rock, and d Kollbecksmoor $(\mathrm{n}=26)$. Note Red color indicates areas with the most fixations; orange/yellow colors show fewer amount of fixations, green color indicates areas with the least amount of fixations. (Color figure online)

counts and duration in VH compared to BG $(p \leq 0.05)$. Similarly, the AOI feet was looked at differently between breeds: WR had a higher amount of fixations and the longest fixation duration $(p \leq 0.05)$ than the rest of the breeds.

\section{Consumers' Associations with Different Breeds (RQ2)}

Results of the TA method show that participants mostly subjectively described each animal (e.g. pretty, healthy) rather than associate it with its use (e.g. meat or egg production). Since the aim of this study was to gain knowledge on what participants 


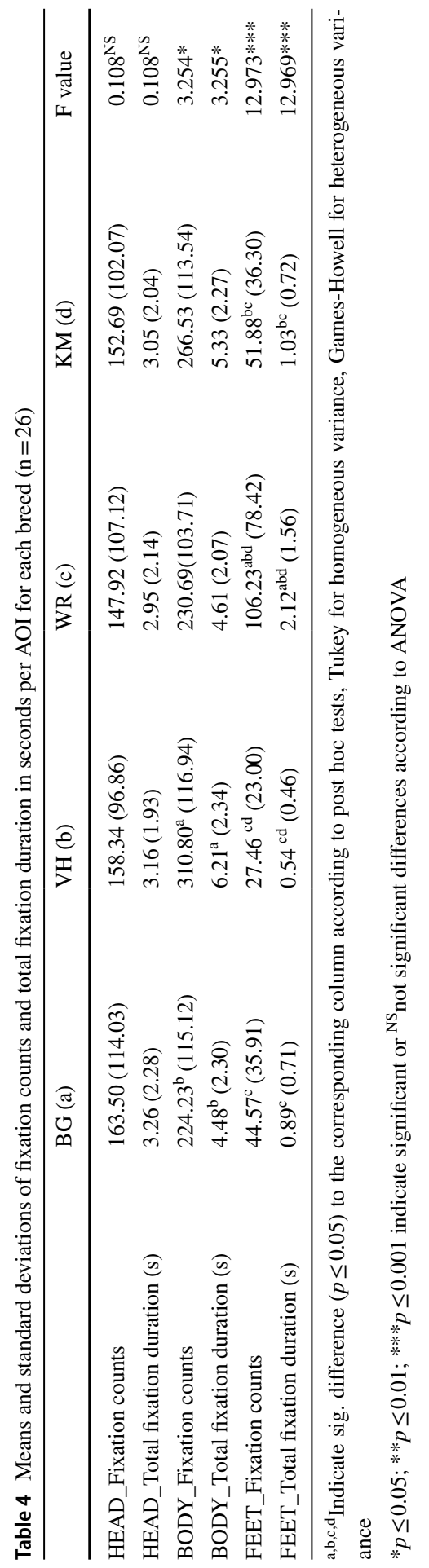


Table 5 Results of the categories "subjective description" and "others" for all breeds

\begin{tabular}{llcl}
\hline Category & Subcategories & $\begin{array}{c}\text { Mentions } \\
(\mathrm{n}=223)\end{array}$ & Most mentioned words \\
\hline Objective description & Animal & 37 & White, black, brown, small beak \\
& Background & 22 & Grass, green, field, outdoors \\
Subjective description & Animal & 119 & Slender, fat, pretty, healthy \\
& Background & 16 & Free-range husbandry \\
Others & Consumption association & 5 & Meat, eat, eggs \\
\hline
\end{tabular}

associate with different chicken breeds, we decided to only use the results of the categories "subjective descriptions" and "others: consumption association" for the quantitative (online) survey. Table 5 shows a summary of the most frequently mentioned words for each category.

Table 3 (Sect. 2.2.1) shows the final list of words used to quantitatively assess differences between the breeds in the online survey.

The socio-demographic characteristics of the sample are described in Table 6. Gender, age and income show a fair represenation of the German population (Destatis 2017). Education levels, although close to the population values, are in some categories over- or underrepresented.

Table 6 Socio-demographic characteristics of the sample $(\mathrm{n}=933)$ and the German population

\begin{tabular}{lcc}
\hline & Sample (\%) & Population (\%) \\
\hline Gender & & \\
Female & 50.8 & 50.7 \\
Male & 49.2 & 49.3 \\
Age & & \\
18-24 years old & 8.8 & 9.1 \\
25-39 years old & 20.7 & 22.6 \\
40-64 years old & 43.5 & 43.1 \\
65 or more years old & 27.0 & 25.2 \\
Education & & \\
No education & 0.5 & 4.0 \\
Lower secondary education & 34.2 & 31.4 \\
High school diploma & 30.9 & 29.4 \\
Technical college & 15.3 & 13.7 \\
University degree & 19.1 & 17.1 \\
Income (net/month) & & 26.5 \\
Less than 1300€ & 25.1 & 39.6 \\
1300€-2599€ & 39.2 & \\
2600€-4999€ & 28.1 & \\
5000€ or more & 7.6 & \\
\hline & & \\
\hline & & \\
\hline
\end{tabular}

Source authors' own data for sample, German population (Destatis 2017) 
Most participants consume (55.9\%) and buy (49.9\%) chicken meat at least once a week, mostly in supermarkets $(46.4 \%)$, discounters $(36.7 \%)$ or directly from the butcher $(5.9 \%) .84 \%$ of participants consume eggs more than once a week, and buy them at least once a week (60.9\%), mostly in discounters $(36.2 \%)$, supermarkets $(35.5 \%)$ or directly from farmers $(14 \%)$.

Table 7 presents mean values of evaluation of the different breeds. All word pairs show differences $(p \leq 0.01)$ between groups. From all 18 pairs of words, only healthiness and age (pair 5 and 11) were rather evaluated as "neither nor". The other 16 pairs were rated as positive, meaning to the word presented on the left side of the scale. As suggested by these results, VH is considered the nicest, happiest, healthiest, most robust, and proudest of all breeds. WR is considered more typical and well-fed. On both pictures showing white breeds (BG and WR)

Table 7 Mean comparison of evaluation of four pictures of different chicken breeds

\begin{tabular}{|c|c|c|c|c|c|c|}
\hline Pair no. & Wording & BG (a) & VH (b) & WR (c) & $\mathrm{KM}(\mathrm{d})$ & $\mathrm{F}$ value \\
\hline 1 & Typical—exotic & $2.17^{\mathrm{bc}}(1.27)$ & $3.01^{\text {acd }}(1.92)$ & $1.96^{\mathrm{abd}}(1.09)$ & $2.25^{\mathrm{bc}}(1.34)$ & $94.95 * * *$ \\
\hline 2 & Nice-ugly & $2.27^{\mathrm{bd}}(1.29)$ & $1.74^{\mathrm{acd}}(1.08)$ & $2.17^{\mathrm{b}}(1.24)$ & $2.11^{\mathrm{ab}}(1.19)$ & $33.28 * * *$ \\
\hline 3 & Happy—sad & $2.84^{\text {bcd }}(1.54)$ & $2.14^{\mathrm{acd}}(1.15)$ & $2.44^{\mathrm{ab}}(1.26)$ & $2.51^{\mathrm{ab}}(1.27)$ & $45.06^{* * *}$ \\
\hline 4 & $\begin{array}{l}\text { Healthy- } \\
\text { unhealthy }\end{array}$ & $2.42^{\text {bcd }}(1.37)$ & $1.82^{\mathrm{acd}}(0.94)$ & $2.05^{\mathrm{ab}}(1.09)$ & $2.14^{\mathrm{ab}}(1.12)$ & $43.62 * * *$ \\
\hline 5 & Fat-thin & $3.01^{\text {bd }}(1.26)$ & $3.36^{\mathrm{acd}}(1.24)$ & $2.98^{\text {bd }}(1.26)$ & $3.92^{\mathrm{abc}}(1.29)$ & $111.12 * * *$ \\
\hline 6 & Big-small & $2.51^{\text {bd }}(1.23)$ & $2.35^{\mathrm{ad}}(1.16)$ & $2.47^{\mathrm{d}}(1.27)$ & $3.02^{\mathrm{abc}}(1.36)$ & $51.73 * * *$ \\
\hline 7 & Natural-overbred & $2.51^{\text {bcd }}(1.48)$ & $2.11^{\mathrm{a}}(1.17)$ & $2.24^{\mathrm{a}}(1.33)$ & $2.25^{\mathrm{a}}(1.22)$ & $15.11 * * *$ \\
\hline 8 & $\begin{array}{l}\text { Well-shaped- } \\
\text { shapeless }\end{array}$ & $2.42^{\mathrm{bc}}(1.41)$ & $2.04^{\mathrm{ad}}(1.07)$ & $2.14^{\mathrm{ad}}(1.18)$ & $2.40^{\mathrm{bc}}(1.24)$ & $22.12 * * *$ \\
\hline 9 & Robust_fragile & $2.53^{\mathrm{bc}}(1.35)$ & $2.13^{\mathrm{acd}}(1.12)$ & $2.29^{\mathrm{abd}}(1.19)$ & $2.58^{\mathrm{bc}}(1.27)$ & $26.65^{* * * *}$ \\
\hline 10 & Strong-weak & $2.30^{\text {bcd }}(1.23)$ & $2.08^{\mathrm{ad}}(1.04)$ & $2.11^{\mathrm{ad}}(1.08)$ & $2.70^{\mathrm{abc}}(1.35)$ & $54.96 * * *$ \\
\hline 11 & Old-young & $4.03^{b c d}(1.27)$ & $4.25^{\mathrm{a}}(1.14)$ & $4.22^{\mathrm{ad}}(1.17)$ & $4.36^{\mathrm{ac}}(1.19)$ & $12.20 * * *$ \\
\hline 12 & Calm-aggressive & $2.46^{\mathrm{b}}(1.21)$ & $2.72^{\text {acd }}(1.32)$ & $2.41^{\mathrm{b}}(1.18)$ & $2.50^{\mathrm{b}}(1.23)$ & $11.16^{* * *}$ \\
\hline 13 & Pet—wild animal & $2.49(1.43)$ & $2.62^{\mathrm{c}}(1.50)$ & $2.41^{\mathrm{b}}(1.40)$ & $2.57(1.44)$ & $3.84 * *$ \\
\hline 14 & Agile-sluggish & $2.97^{\text {bcd }}(1.52)$ & $2.52^{\mathrm{a}}(1.21)$ & $2.62^{\mathrm{a}}(1.38)$ & $2.56^{\mathrm{a}}(1.24)$ & $21.95 * * *$ \\
\hline 15 & Well-fed-rickety & $2.11^{\mathrm{cd}}(1.10)$ & $2.20^{\mathrm{cd}}(1.07)$ & $1.97^{\mathrm{abd}}(1.01)$ & $2.61^{\mathrm{abc}}(1.28)$ & $56.03 * * *$ \\
\hline 16 & Tasty_disgusting & $2.89^{c}(1.31)$ & $2.76^{\mathrm{d}}(1.30)$ & $2.72^{\mathrm{ad}}(1.30)$ & $2.93^{\mathrm{bc}}(1.30)$ & $5.66^{* *}$ \\
\hline 17 & $\begin{array}{l}\text { Appetizing-unap- } \\
\text { petizing }\end{array}$ & $2.94^{\mathrm{bc}}(1.40)$ & $2.75^{\mathrm{ad}}(1.32)$ & $2.76^{\mathrm{ad}}(1.38)$ & $2.95^{\mathrm{bc}}(1.35)$ & $5.8 * * *$ \\
\hline 18 & Proud-crouched & $2.89^{\text {bcd }}(1.54)$ & $2.06^{\text {acd }}(1.12)$ & $2.34^{\mathrm{ab}}(1.24)$ & $2.42^{\mathrm{ab}}(1.23)$ & $66.75 * * *$ \\
\hline
\end{tabular}

Means, standard deviations and F-values are shown $(\mathrm{n}=933)$

Scale: 1 positive (left side) adjective, 4 neither nor, 7 negative (right side) adjective

$B G$ Bresse Gauloise, $V H$ Vorwerkhuhn, WR White Rock, $K M$ Kollbecksmoor

${ }^{\mathrm{a}, \mathrm{b}, \mathrm{c}, \mathrm{d}}$ Indicate sig. difference $(p \leq 0.05)$ to the corresponding column according to post hoc tests, Tukey for homogeneous variance, Games-Howell for heterogeneous variance

$* p \leq 0.05 ; * * p \leq 0.01 ; * * * p \leq 0.001$ indicate significance or ${ }^{\mathrm{NS}}$ not significant differences according to ANOVA 
the animals were considered fatter. $\mathrm{VH}$ and $\mathrm{WR}$ are considered more appetizing and tastier than BG and KM.

Participants' associations of the breeds with egg or meat production show significant differences between breeds. BG and WR are evaluated as more suitable for meat and egg production when compared to VH and KM $(p \leq 0.05)$. Similarly, BG and WR are evaluated as more likely to lay many eggs and eggs with white color than $\mathrm{VH}$ and $\mathrm{KM}$. On the other hand, $\mathrm{VH}$ and $\mathrm{KM}$ are significantly more associated to laying brown eggs than BG and WR. However, all breeds are evaluated neutral when considering them for a barbecue; although WR is considered more suitable for a barbecue than KM. Table 8 presents the results for each breed in more detail.

When consumers were exposed to the same four pictures and asked "Please remember the last time you consumed chicken meat. Which picture comes to your mind? Why?", 44\% answered "I do not know", 24\% WR, 14\% BG, 9\% KM and 9\% VH. Only $13 \%(n=125)$ of participants which answered "I do not know" explained their choice. From these participants, 30 (3\% from total participants) explained their answer with statements like: "I am absolutely not familiar with chicken breeds", "in the end product/package it is not written which type/breed of animal it is", "when I eat meat I do not associate it with any breed; I do not know anything about chicken breeds". Interestingly, statements related to the dissociation of animals to meat, such as "I only ate the meat and not the chicken", "When I eat chicken meat I do not think about how the living animal looked like", "My meat does not have feathers", "I do not think about that" were also made by $3 \%$ of participants.

The $38 \%$ of participants which associated the pictures of either WR or BG, both white breeds, to the meat they ate lately explained their choices with statements

Table 8 Mean comparison of evaluation of four pictures of different chicken breeds associated to consumption

\begin{tabular}{llllll}
\hline Wording & BG (a) & VH (b) & WR $(\mathrm{c})$ & KM $(d)$ & F value \\
\hline $\begin{array}{l}\text { This chicken is suitable for } \\
\text { meat production }\end{array}$ & $2.76^{\mathrm{bd}}(1.47)$ & $3.05^{\mathrm{acd}}(1.59)$ & $2.71^{\mathrm{bd}}(1.47)$ & $3.25^{\mathrm{abc}}(1.56)$ & $25.1^{* * *}$ \\
$\begin{array}{l}\text { This chicken is suitable for egg } \\
\text { production }\end{array}$ & $2.41^{\mathrm{bd}}(1.33)$ & $3.08^{\mathrm{acd}}(1.76)$ & $2.35^{\mathrm{bd}}(1.33)$ & $2.62^{\mathrm{abc}}(1.35)$ & $48.68^{* * *}$ \\
$\begin{array}{l}\text { This chicken will certainly lay } \\
\text { many eggs }\end{array}$ & $2.74^{\mathrm{bd}}(1.34)$ & $3.36^{\mathrm{acd}}(1.65)$ & $2.66^{\mathrm{bd}}(1.30)$ & $3.03^{\mathrm{abc}}(1.33)$ & $46.26^{* * *}$ \\
$\begin{array}{l}\text { It looks as if it lays brown eggs } \\
\text { It looks as if it lays white eggs }\end{array}$ & $3.73^{\mathrm{bd}}(1.50)$ & $3.53^{\mathrm{ac}}(1.79)$ & $4.71^{\mathrm{bd}}(1.50)$ & $3.38^{\mathrm{ac}}(1.52)$ & $198.37^{*} * *$ \\
$\begin{array}{c}\text { This chicken is well suited for } \\
\text { a barbecue }\end{array}$ & $3.49(1.61)$ & $4.72^{\mathrm{acd}}(1.56)$ & $3.06^{\mathrm{bd}}(1.59)$ & $4.42^{\mathrm{abc}}(1.46)$ & $309.24 * * *$ \\
\hline
\end{tabular}

Means, standard deviations and F-values are shown $(n=933)$

Scale: 1 totally agree, 4 neither nor, 7 totally disagree

$B G$ Bresse Gauloise, $V H$ Vorwerkhuhn, WR White Rock, $K M$ Kollbecksmoor

a,b,c,d Indicate sig. difference $(p \leq 0.05)$ to the corresponding column according to post hoc tests, Tukey for homogeneous variance, Games-Howell for heterogeneous variance

$* p \leq 0.05 ; * * p \leq 0.01 ; * * * p \leq 0.001$ indicate significant differences according to ANOVA between breeds 
like "it looks like a typical chicken as you know it", "typical chicken for slaughter", "because it is a typical chicken and it is used for meat production", "looks like a conventional German chicken". Lastly, the $18 \%$ of participants that chose brown breeds (KM and $\mathrm{VH})$ explained their answers with statements like "used to know only this variety", "we had chickens like this at home", "I know that from my childhood", "reminds me of the typical chickens we used to have ourselves".

Similarly, when asked "Please remember the last time you consumed eggs. Which picture comes to your mind? Why?", the most selected option $(42 \%)$ was a white breed with $28 \%$ for WR and $14 \%$ for BG, while $30 \%$ answered "I do not know", followed by KM (17\%) and VH (11\%).

\section{Consumers' Acceptance of Animal Pictures When Buying Meat (RQ3)}

Participants were presented with 16 statements related to the meat-paradox, where two statements directly measured participants' willingness to see animal pictures when buying meat. Most participants $(54.7 \%)$ disagreed with the statement "I would like to buy meat with pictures of the animals on the package" $(\mu=5.12, \sigma=1.65)$ while $27.2 \%$ were neutral and $18.1 \%$ agreed with it. Similarly, $52.8 \%$ of participants disagreed with the statement "I would like to see what the animal looked like before it was slaughtered" ( $\mu=5.03, \sigma=1.89), 36.8 \%$ were neutral and $10.4 \%$ agreed.

Participants who agreed or were neutral to seeing what the animal looked like before slaughter and to seeing pictures of animals on the packages $(31.3 \%, \mathrm{n}=292)$ were grouped ("accepting consumers") and compared to the rest of participants ("non-accepting participants"). Results (Table 9) show that accepting consumers eat less meat, buy more organic and are significantly more aware of the slaughter process when eating meat than the rest of participants. Although both groups rather think that animals are not doing very well in husbandry systems, accepting consumers feel more empathy with animals and, when buying meat, they try to ensure that animals were kept in good conditions. Non-accepting participants in contrast try to not associate chicken meat with an animal and do not like to think about the origin of the chicken meat more than accepting consumers. The non-accepting participants also agree more strongly that it is necessary that animals are kept for human nutrition and that they cannot do anything about the current animal husbandry systems. Table 9 shows these results in more detail.

When evaluating whether the two groups (accepting consumers and non-accepting participants) associated the use of the breeds for egg or meat production differently, differences were found regarding the associations with meat: less of the "accepting consumers" answered with "I do not know". 


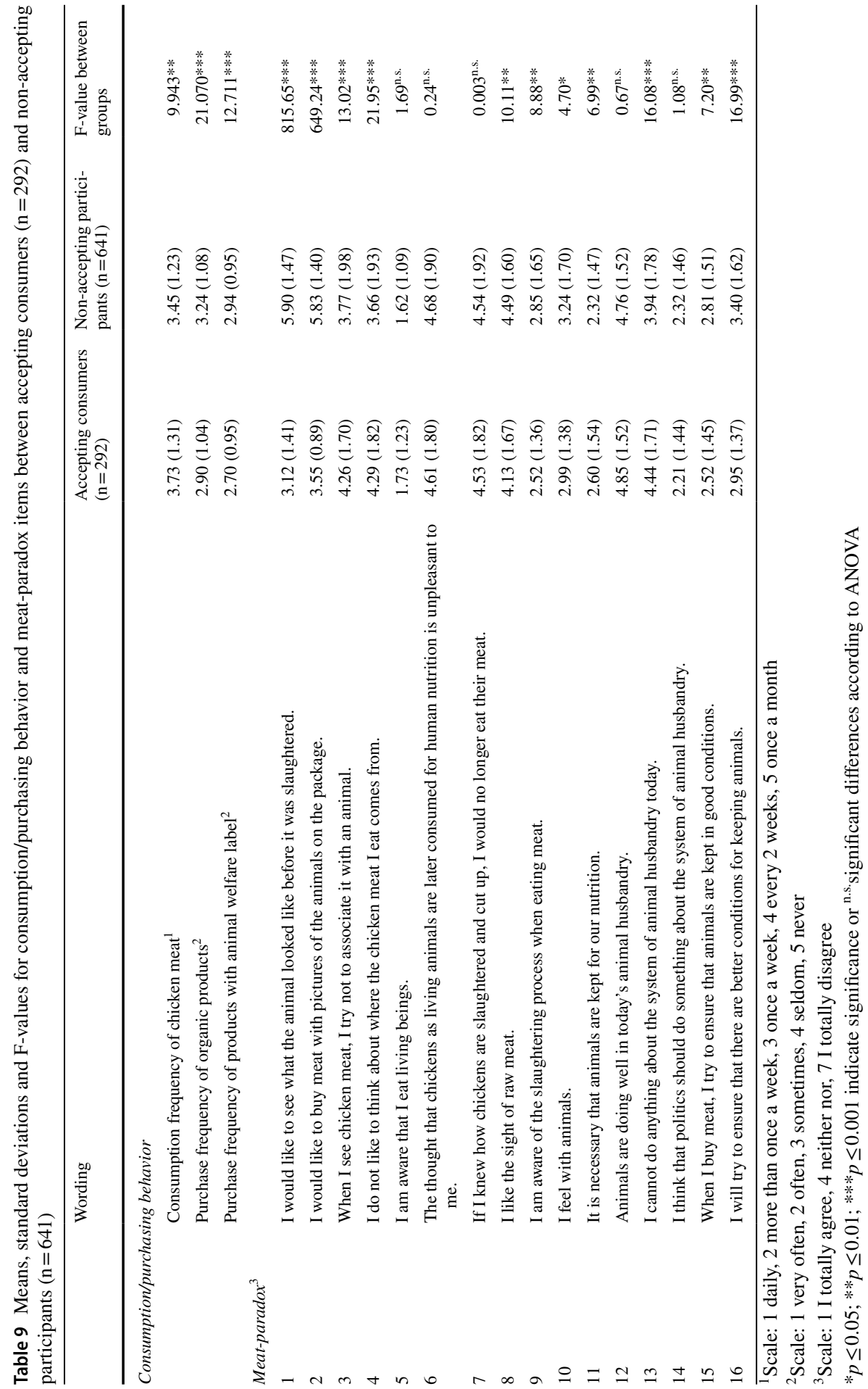




\section{Discussion}

\section{Consumers' Observations When Presented with Pictures of Different Chicken Breeds (RQ1)}

We find that participants' eye movements, in general, are similar for all four breeds. Regardless of the breed, participants look at the body and face for the longest time. These results support previous findings where participants also looked mostly at the body and face of farm animals (pigs) when presented in pictures (Busch et al. 2017) and where both humans and animals (chimpanzees) looked mostly at the face of other animals or humans when different pictures were shown (Kano and Tomonaga 2009). The fixation on the face area could be attributed to the presence of the eyes. Birmingham et al. (2007) suggest that people look at the eyes because these are informative regions, e.g. they can convey emotion.

Looking at fixation counts and durations it must be noted that the AOI body of the animal is fixated more often and longer comapred to the head, although the head is predominant in the heat maps. This difference is attributed to the fact that heat maps are calculated on single data points whereas the counts and durations of the AOIs are accumulated values for the whole AOI of the pictures.

Regarding fixation durations of the chickens, clear differences can be seen for the body and feet of the animals. The longer fixation time on VH's body can be attributed to the unfamiliarity with this chicken breed and in particular with the general perception that $\mathrm{VH}$ is the most unknown of the four breeds. Wang and Green (1994) explain how familiarity with objects make visual search faster compared to objects that are unfamiliar to viewers.

Based on these results, we suggest that when looking at the head of the chickens, consumers make no difference between breeds or feather color. However, when participants look at the body and feet, they evaluate breeds of the same color very similar and different from breeds of other color. The change in visual attention suggests that the different color of the plumage of brown breeds might stimulate to watch the entire animal instead of focusing on some parts. Results indicate a color based evaluation of chickens, rather than a breed based evaluation, which is expected since most participants are not familiar with chicken breeds.

Based on the lack of knowledge that most consumers have about chicken breeds, color attribution might be an interesting feature to target since consumers seem to pay more attention to this attribute.

Therefore, the color of a breed can be used as a bridge to expand consumer knowledge on specific traditional breeds. A German breeding company from the organic market named "Ökologische Tierzucht Gemeinnützige GmbH" has used this approach and uses colors of animals as commercial names for specific breeds, such as "coffee" and "cream" for a white-brown-black breed and a white breed, respectively (ÖTZ 2016). 


\section{Consumers' Associations with Different Breeds (RQ2)}

From the TA protocols we can see that participants mostly use subjective adjectives (e.g. pretty, healthy) to describe the animals in the different pictures. Only five participants (17\%) make a direct association to consumption (e.g. eggs, meat, eat), thus showing that spontaneously, most participants do not associate animals to meat.

Results from the semantic differential scale indicate that BG is considered as a typical, calm, pet and well-fed animal. VH and WR are considered nice, happy, and healthy animals; both were also perceived as tasty and appetizing. The tasty and appetizing appearance of $\mathrm{VH}$ and WR seem to be associated with the physical shape of the animals' body, i.e. bigger, well-shaped, stronger and more robust.

When associating the chickens with a specific type of use (e.g. meat or eggs), participants evaluated, just by looking at the color, white breeds (BG and WR) more suitable for meat and white egg production and brown breeds ( $\mathrm{VH}$ and $\mathrm{KM}$ ) more suitable for brown egg production. Despite of this, there is still a small group of consumers who see brown breeds as typical because it reminds them of the chickens they used to have or see when growing up.

Although each breed has unique characteristics, the lack of familiarity with them makes them be seen as either a "white or brown" or a "meat or egg" breed. We found that most consumers are, in general, not familiar with chicken breeds. However, when looking at pictures of breeds, they have associations to each one. Nonetheless, we can conclude that when looking at pictures of different chicken breeds, participants ignore the attribute of "breed" because of their unfamiliarity with it and make appearance-based, mostly feathering-based, associations. Therefore we confirm our first hypothesis: chicken breeds are perceived differently among consumers due to their different phenotypes.

\section{Consumers' Acceptance of Animal Pictures When Buying Meat (RQ3)}

As expected, most participants are neither interested in seeing pictures of the animals on the meat package nor in seeing what animals looked like before slaughter. These participants try to dissociate chicken meat from a living animal significantly more than participants interested in seeing what the animal looked like. These results support previous findings where participants showed more empathy towards the animal and less willingness to eat its meat when a picture was shown along with the product (Kunst and Hohle 2016). Our results also show that these participants consider it necessary that animals are kept for human consumption and feel that they cannot do anything about current animal husbandry systems. Hence, we confirm our second hypothesis: chicken meat, although usually perceived differently than red meat (Kubberød et al. 2002), suffers from the same "meat-paradox"-effect as red meat.

Our results also confirm our expectations that there is a smaller group of participants that is interested in seeing what the animal looked like before slaughter and interested in seeing pictures of animals on the meat packages. These participants 
consume less chicken meat than the rest and purchase more products with higher animal welfare standards and organic standards. This agrees with other studies where eating less meat was linked (in part) to a higher engagement of consumers to "green" goals, such as organic production methods (de Boer et al. 2016; Heerwagen et al. 2014) and animal concerns (Graça et al. 2015; de Boer et al. 2017; Rothgerber 2015). This sustainable behavior (e.g., consuming less meat, purchasing organic products, purchasing products with animal welfare label) demonstrates that some consumer segments are interested in production methods. Studies (Graça et al. 2015; de Boer et al. 2017) show that information regarding the environmental impacts of meat production and consumption increased consumers' willingness to reduce meat consumption. This shows that information may lead to a change in consumption behavior towards a more ethical and sustainable way.

Our results suggest that when these accepting consumers consider the "meat-animal origin", they react to the "meat-paradox" by reducing their meat consumption. This behavior has also been shown by other studies (Hoogland et al. 2005; Piazza et al. 2015). Similarly, when consumers consider that animals are being killed for human consumption some might react to it by preferring to purchase meat with higher animal welfare standards. This has also been revealed by Hoogland et al. (2005), Hölker et al. (2019), Rothgerber (2015), and Piazza et al. (2015). For this group of consumers, the use of pictures may add value to the product by providing easily understandable information about breeds and making the product more personal. These findings could also be relevant for companies in the organic market or those working with animal welfare labels. The presentation of pictures could fit into the "less but better" strategy in this consumer segment.

As participants were asked which picture came to their mind when remembering the last time they consumed chicken meat and eggs, both groups made more associations with a breed when thinking about eggs than meat. These results suggest that these participants also suffer from the "meat-paradox" effect. Additionally, when associating the pictures with meat, those who accept pictures of the animals made more associations to breeds than those who reject pictures. This also confirms that participants interested in pictures try to think more about the animal they consume, while rejecting consumers avoid thinking about the animals.

\section{Conclusion}

This study is one of the first to evaluate consumers' attention and associations with pictures of traditional chicken breeds. Its importance relies in the need of communication tools to allow consumers to get acquainted with these breeds and the benefits of purchasing their products (e.g., no killing of day-old chicks, conservation of biodiversity). Results of this study show that consumers' knowledge and familiarity with chicken breeds is very low. In general, consumers mainly look at the body and face of animals and fixate on the brown chickens' body the longest, suggesting a longer attraction due to unfamiliarity. By looking at pictures, white breeds are considered better suited for meat and egg (particularly white egg) production, while brown breeds are considered to lay brown eggs. 
Given the widespread ignorance of consumers of animal breeds, it is difficult to use biodiversity as a marketing tool. Very few consumers are able to recognize the special features of the traditional breeds. In this respect, our results are in line with the experiences of small-scale farmers who strive to preserve old breeds and are not very successful on the market, at least in Germany.

In general, using pictures of animals as a way to promote breeds in a mass market is not recommendable, as most consumers do not want to see pictures of living animals on packages of the meat products they consume. Nevertheless, pictures of traditional breeds could be used in smaller, alternative market segments to gain attention and to communicate in an effective way the type of breed reared and the benefits of this particular breed. Our results show that the consumer segment ready for this information purchases chicken meat with less frequency and products with animal welfare and organic standard more frequently than the rest of consumers, suggesting a higher engagement to sustainability issues. For this particular segment, the availability of these pictures and more information related to the animal breed (e.g., dual-purpose, traditional), its husbandry system (e.g., free range), the type of feed (e.g., regional cereals/legumes), and ethical conditions (e.g., no killing of day-old chicks) could be transferred.

Authors' Contributions The authors contributed to this research article the following way: design, CE, $\mathrm{AR}$ and AS; analysis of data, CE; interpretation of data, CE, GB, AR; writing - original draft preparation, CE; writing - review and editing, GB; AR; AS All authors have read and approved the final manuscript and agree to be accountable for all aspects of the work.

Funding Open Access funding enabled and organized by Projekt DEAL. This study was funded by the Lower Saxony Ministry of Science and Culture (Niedersächsisches Ministerium für Wissenschaft und Kultur), Grant Number: MWK 11-76251-99-30/16.

Availability of Data and Material Raw data available at https://doi.org/10.17632/bz8bjdg4f5.1.

\section{Compliance with Ethical Standards}

Conflict of interest The authors declare no conflicts of interest. The funders had no role in the design of the study; in the collection, analyses, or interpretation of data; in the writing of the manuscript, or in the decision to publish the results.

Open Access This article is licensed under a Creative Commons Attribution 4.0 International License, which permits use, sharing, adaptation, distribution and reproduction in any medium or format, as long as you give appropriate credit to the original author(s) and the source, provide a link to the Creative Commons licence, and indicate if changes were made. The images or other third party material in this article are included in the article's Creative Commons licence, unless indicated otherwise in a credit line to the material. If material is not included in the article's Creative Commons licence and your intended use is not permitted by statutory regulation or exceeds the permitted use, you will need to obtain permission directly from the copyright holder. To view a copy of this licence, visit http://creativecommons.org/licen ses/by/4.0/. 


\section{References}

Aerts, S., Boonen, R., Bruggeman, V., De Tavernier, J., \& Decuypere, E. (2009). Culling of day-old chicks: Opening the debates of Moria? In A.S. Olsson, S.M. Araújo, \& M. Fátima Vieira (Eds.), Food futures: Ethics, science and culture (pp. 117-122). Wageningen: Wageningen Academic Publishers.

Albersmeier, F. \& Spiller, A. (2008). Supply chain reputation in der fleischwirtschaft. Discussion paper (0811), Department of Agricultural Economics and Rural Development, University of Goettingen, Goettingen, Germany. https://www.econstor.eu/bitstream/10419/29661/1/588532940.pdf. Accessed July 10, 2020.

Balcombe, K., Fraser, I., \& McSorley, E. (2015). Visual attention and attribute attendance in multi-attribute choice experiments. Journal of Applied Econometrics, 30, 447-467. https://doi.org/10.1002/ jae.2383.

Bastian, B., \& Loughnan, S. (2016). Resolving the meat-paradox: a motivational account of morally troublesome behavior and its maintenance. Personality and Social Psychology Review, 21, 1-22. https:// doi.org/10.1177/1088868316647562.

Bäuerliche Erzeugergemeinschaft Schwäbisch Hall (BESH). Züchtervereinigung Schwäbisch-Hällisches Landschwein. (2019). https://www.besh.de/erzeuger/zvsh/. Accessed November 14, 2019.

Belk, K. E., Woerner, D. R., Delmore, R. J., Tatum, J. D., Yand, H., \& Sofod, J. N. (2014). The meat industry: Do we think and behave globally or locally? Meat Science, 98, 556-560. https://doi. org/10.1016/j.meatsci.2014.05.023.

Birmingham, E., Bischof, W., \& Kingstone, A. (2007). Why do we look at people's eyes? Journal of Eye Movement Research, 1, 1-6. https://doi.org/10.16910/jemr.1.1.1.

Böhm, J., Albersmeier, A., Spiller, A., \& Zühlsdorf, A. (2009). Zukunftsfaktor gesellschaftliche Akzeptanz: Kommunikation mit der Öffentlichkeit-Mehr als Krisen-PR. In J. Böhm, F. Albersmeier, \& A. Spiller (Eds.), Die Ernährungswirtschaft im Schweinwerferlicht der Öffentlichkeit (pp. 5-16). Lohmar: Eul Verlag.

Bruijnis, M. R. N., Blok, V., Stassen, E. N., \& Gremmen, H. G. J. (2015). Moral „Lock-In” in responsible innovation: The ethical and social aspects of killing day-old chicks and its alternatives. Journal of Agricultural and Environmental Ethics, 28, 939-960. https://doi.org/10.1007/s10806-015-9566-7.

Brümmer, N., Christoph-Schulz, I., \& Rovers, A. K. (2017). Consumers' perspective on dual-purpose chickens. Proceedings in System Dynamics and Innovation in Food Networks., 1, 164-169. https:// doi.org/10.18461/pfsd.2017.1717.

Bundesanstalt für Landwirtschaft und Ernährung (BLE). (2019). Einheimische nutztierrassen in deutschland und rote liste gefährdeter nutztierrassen 2019. https://www.genres.de/fileadmin/SITE_ MASTER/content/Publikationen/TGR_Rote_Liste.pdf Accessed May 15, 2020.

Bundesministerium für Ernährung und Landwirtschaft (BMEL). (2019). Alternativen zum Töten männlicher Küken. https://www.bmel.de/DE/themen/tiere/tierschutz/tierwohl-forschung-in-ovo.html Accessed March 03, 2020.

Busch, G., Gauly, S. A., \& Spiller, A. (2017). Ich sehe was, was du nicht siehst: Eine Eye-Tracking Studie zur Betrachtung und Bewertung von Bildern aus der Schweinemast. German Journal of Agricultural Economic, 2, 65-84.

Busse, M., Kernecker, M. L., Zscheischler, J., Zoll, F., \& Siebert, R. (2019). Ethical concerns in poultry production: A German consumer survey about dual purpose chickens. Journal of Agricultural and Environmental Ethics, 32, 905-925. https://doi.org/10.1007/s10806-019-09806-y.

Damme, K. (2015). Economics of dual-purpose breeds-A comparison of meat and egg production using dual purpose breeds versus conventional broiler and layer strains. LOHMANN Information, 50(2), 4-9.

De Boer, J., de Witt, A., \& Aiking, H. (2016). Help the climate, change your diet: A cross-sectional study on how to involve consumers in a transition to a low-carbon society. Appetite, 98, 19-27. https://doi. org/10.1016/j.appet.2015.12.001.

De Boer, J., Schösler, H., \& Aiking, H. (2017). Towards a reduced meat diet: Mindset and motivation of young vegetarians, low, medium and high meat-eaters. Appetite, 113, 387-397. https://doi. org/10.1016/j.appet.2017.03.007.

Destatis. (2017). Statistisches jahrbuch. Deutschland und internationales. Wiesbaden, Germany: Statistisches Bundesamt. https://www.destatis.de/Migration/DE/Publikationen/StatistischesJahrbuch/Stati stischesJahrbuch2017.pdf?_blob=publicationFile Accessed November 14, 2019. 
Duchowski, A. T. (2002). A breadth-first survey of eye-tracking applications. Behavior Research Mehods, Instruments \& Computers, 34(4), 455-470. https://doi.org/10.3758/BF03195475.

Ermann, M. (2018). Stakeholderorientiertes Kommunikationsmanagement in der Agrar und Ernährungswirtschaft. Goettingen: Dr. Kovač.

Fermet-Quinet, E., \& Bussière, C. (2010). Small commercial and family poultry production in France: characteristics, and impact of HPAI regulations. FAO smallholder poultry production paper no. 3. Food and Agriculture Organization of the United Nations. Rome, Italy. http://www.fao.org/3/al673e/ al673e00.pdf Accessed July 20, 2020.

Festinger, L. (1957). A theory of cognitive dissonance. Stanford: Stanford University Press.

Fraser, D. (2008). Animal welfare and the intensification of animal production. In P. B. Thompson (Ed.), Ethics OF intensification: agricultural development and cultural change (pp. 167-189). Rome: FAO.

Frison, C., \& Coolsaet, B. (2018). Genetic resources for food and agriculture as commons. In T. Ferrando, O. de Schutter, U. Mattei, \& J. L. Vivero-Pol (Eds.), Routledge handbook of food as a commons. New York: Taylor \& Francis.

Gangnat, I. D. M., Mueller, S., Kreuzer, M., Messikomer, R. E., Siegrist, M., \& Visschers, V. H. M. (2018). Swiss consumers 'willingness to pay and attitudes regarding dual-purpose poultry and eggs. Poultry Science, 97, 1089-1098. https://doi.org/10.3382/ps/pex397.

Graça, J., Oliveira, A., \& Calheiros, M. M. (2015). Meat, beyond the plate. Data-driven hypotheses for understanding consumer willingness to adopt a more plant-based diet. Appetite, 90, 80-90. https:// doi.org/10.1016/j.appet.2015.02.037.

Harmon-Jones, E., \& Harmon-Jones, C. (2007). Cognitive dissonance theory after 50 years of development. Zeitschrift für Sozialpsychologie, 38, 7-16. https://doi.org/10.1024/0044-3514.38.1.7.

Heerwagen, L. R., Andersen, L. M., Christensen, T., \& Sandøe, P. (2014). Can increased organic consumption mitigate climate changes? British Food Journal. https://doi.org/10.1108/ BFJ-02-2013-0049.

Hölker, S., von Meyer-Höfer, M., \& Spiller, A. (2019). Animal ethics and eating animals: consumer segmentation based on domain-specific values. Sustainability, 11, 3907. https://doi.org/10.3390/su111 43907.

Holmqvist, K., Nyström, M., \& Mulvey, F. (2012). Eye tracker data quality: What it is and how to measure it. Proceedings of the Symposium on Eye Tracking Research and Applications. https://doi. org/10.1145/2168556.2168563.

Hoogland, C., de Boer, J., \& Boersema, J. J. (2005). Transparency of the meat chain in the light of food culture and history. Appetite, 45, 15-23. https://doi.org/10.1016/j.appet.2005.01.010.

Kano, F., \& Tomonaga, M. (2009). How chimpanzees look at pictures: a comparative eye-tracking study. Proceedings of the Royal Society B, 276, 1949-1955. https://doi.org/10.1098/rspb.2008.1811.

Krautwald-Junghanns, M.-E., Cramer, K., Fischer, B., Förster, A., Galli, R., Kremer, F., et al. (2018). Current approaches to avoid the culling of day-old male chicks in the layer industry, with special reference to spectroscopic methods. Poultry Science, 97(3), 749-757. https://doi.org/10.3382/ps/pex389.

Kubberød, E., Ueland, Ø., Tronstad, A., \& Risvik, E. (2002). Attitude towards meat and meat-eating among adolescents in Norway: a qualitative study. Appetite, 38, 53-62. https://doi.org/10.1006/ appe.2002.0458.

Kunst, J. R., \& Hohle, S. M. (2016). Meat eaters by dissociation: How we present, prepare and talk about meat increases willingness to eat meat by reducing empathy and disgust. Appetite, 105, 758-774. https://doi.org/10.1016/j.appet.2016.07.009.

La Volaille de Bresse. (2015). http://www.pouletdebresse.fr/?lang=en Accessed November 14, 2019.

Leenstra, F., Munnichs, G., Beekman, V., van den Heuvel-Vromans, E., Aramyan, L., \& Woelders, H. (2011). Killing day-old chicks? Public opinion regarding potential alternatives. Animal Welfare, 20, $37-45$.

Loughnan, S., Haslam, N., \& Bastian, B. (2010). The role of meat consumption in the denial of moral status and mind to meat animals. Appetite, 55, 156-159. https://doi.org/10.1016/j.appet.2010.05.043.

Mueller, S., Kreuzer, M., Siegrist, M., Mannale, K., Messikommer, R. E., \& Gangnat, I. D. M. (2018). Carcass and meat quality of dual-purpose chickens (Lohmann Dual, Belgian Malines, Schweizerhuhn) in comparison to broiler and layer chicken types. Poultry Science, 97, 3325-3336. https://doi. org/10.3382/ps/pey172.

Oekologische Tierzucht Gemeinnützige GmbH (ÖTZ). Zweinutzung Coffee und Cream. (2016). https:// www.oekotierzucht.de/oetz-zweinutzungshuhn Accessed December 2, 2019. 
Padhi, M. K. (2016). Importance of indigenous breeds of chicken for rural economy and their improvements for higher production performance. Scientifica, 6, 1-9. https://doi.org/10.1155/2016/2604685.

Piazza, J., Ruby, M. B., Loughnan, S., Luong, M., Kulik, J., Watkins, H., et al. (2015). Rationalizing meat consumption. The 4Ns. Appetite, 91, 114-128. https://doi.org/10.1016/j.appet.2015.04.01.

Raschke, M., Blascheck, T., \& Burch, M. (2014). Visual analysis of eye tracking data. In W. Huang (Ed.), Handbook of human centric visualization (pp. 391-409). New York: Springer.

Rothgerber, H. (2013). Real men don't eat (vegetable) quiche: masculinity and the justification of meat consumption. Psychology of Men and Masculinity, 14(4), 363-375. https://doi.org/10.1037/a0030379.

Rothgerber, H. (2015). Can you have your meat and eat it too? Conscientious omnivores, vegetarians, and adherence to diet. Appetite, 85, 196-203. https://doi.org/10.1016/j.appet.2014.10.012.

Spalona, A., Ranvig, H., Cywa-Benko, K., Zanon, A., Sabbioni, A., Szalay, I., et al. (2007). Population size in conservation of local chicken breeds in chosen European countries. Archiv für Geflügelkunde, $71(2), 49-55$.

Tobiipro. Tobii Studio-User's Manual Version 3.4.5. (2016). https://www.tobiipro.com/siteassets/tobii -pro/user-manuals/tobii-pro-studio-user-manual.pdf Accessed October 8, 2019.

Tobiipro-FAQs. (2018). https://connect.tobiipro.com/s/article/Sample-percentage-calculated-in-Studi o-Lab-and-Controller?language=en_US Accessed October 19, 2020.

van Someren, M. W., Barnard, Y. F., \& Sandberg, J. A. C. (1994). Analyzing the protocols. The think aloud method: a practical guide to modelling cognitive processes (pp. 117-139). London: Academic Press.

Verrier, E., Tixier-Boichard, M., Bernigaud, R., \& Naves, M. (2005). Conservation and adaptation of local livestock breeds: usefulness of niche products and/or adaptation to specific environments. Animal Genetic Resources Information, 36, 21-31. https://doi.org/10.1017/S1014233900005538.

Wahl, T. I., Shi, H., \& Mittelhammer, R. C. (1995). A hedonic price analysis of characteristics of Japanese Wagyu beef. Agribusiness, 11, 35-44. https://doi.org/10.17221/206/2014-AGRICECON.

Wang, Q., \& Green, M. (1994). Familiarity and pop-out in visual search. Perception and Psychophysics, 56, 495-500. https://doi.org/10.3758/BF03206946.

Wedel, M., \& Pieters, R. (2006). Eye tracking for visual marketing. Foundations and Trends in Marketing, 1, 231-320. https://doi.org/10.1561/1700000011.

Weigend, S., Stricker, K., \& Röhrßen, R.-G. (2009). Establishing a conservation flock for "Vorwerkhuhn" chicken breeds-A case study of in situ conservation of local chicken breeds in Germany. Animal Genetic Resources Information, 44, 87-88. https://doi.org/10.1017/S1014233900002893.

Westbury, H. R., \& Neumann, D. L. (2008). Empathy-related responses to moving film stimuli depicting human and non-human animal targets in negative circumstances. Biological Psychology, 78, 66-74. https://doi.org/10.1016/j.biopsycho.2007.12.009.

Publisher's Note Springer Nature remains neutral with regard to jurisdictional claims in published maps and institutional affiliations.

\section{Affiliations}

\section{Cynthia I. Escobedo del Bosque ${ }^{1}$ (D) Gesa Busch ${ }^{1} \cdot$ Achim Spiller $^{1} \cdot$ Antje Risius $^{1}$}

Gesa Busch

gesa.busch@agr.uni-goettingen.de

Achim Spiller

a.spiller@agr.uni-goettingen.de

Antje Risius

a.risius@uni-goettingen.de

1 Department of Agricultural Economics and Rural Development, University of Goettingen, Platz der Göttinger Sieben 5, 37073 Goettingen, Germany 